\title{
A Broadband Conformal Phased Array Antenna on Spherical Surface
}

\author{
Dan Sun, ${ }^{1,2}$ Rong Shen, ${ }^{1,2}$ and Xuequan Yan ${ }^{1,2}$ \\ ${ }^{1}$ AVIC LEIHUA Electronic Technology Research Institute, No. 796 Liang Xi Road, Jiangsu, Wuxi 214063, China \\ ${ }^{2}$ Aviation Key Laboratory of Science and Technology on AISSS, No. 796 Liang Xi Road, Jiangsu, Wuxi 214063, China \\ Correspondence should be addressed to Dan Sun; sun_dan@sina.com
}

Received 10 October 2013; Revised 29 January 2014; Accepted 24 February 2014; Published 24 March 2014

Academic Editor: Xiuping Li

Copyright (c) 2014 Dan Sun et al. This is an open access article distributed under the Creative Commons Attribution License, which permits unrestricted use, distribution, and reproduction in any medium, provided the original work is properly cited.

\begin{abstract}
A Ku-band wideband conformal array antenna with $13 \times 19$ elements is presented in the paper. The array has a spherical structure, and its element is a proximity-coupled stacked patches antenna with a cavity-backed ground plane. The stacked patches and the cavity produce multiple coupled resonances, which enhance the bandwidth of the element extremely. A simulated model with the reasonable dimensions is framed with the coupling analyses, and the effective simulated results and good computing efficiency are obtained simultaneously. The measured results of the center embedded element in the whole array show a bandwidth exceeding $40 \%$ (VSWR $<2$ ), which is close to the simulated matching performance.
\end{abstract}

\section{Introduction}

Recently, active electronically scanned array (AESA) systems have been widely applied in aircrafts. However, the antenna arrays in these systems are basically planar, and it is difficult with these arrays to achieve the integration with platforms. Accordingly, the aerodynamic performance and the RCS of platforms are affected. One effective solution is to employ conformal phased arrays instead of planar arrays. Furthermore, conformal arrays can afford larger beam coverage range besides planar arrays. Hence, the designs of conformal array antennas have been an attractive research field, and many significant investigations have been reported, such as the conformal waveguide slot arrays [1] and the conformal microstrip patch arrays [1-11]. As compared to conformal waveguide slot arrays, conformal microstrip patch arrays have the advantage of lighter weight, smaller size, and better integration with aircrafts. Thus, a clear majority of conformal arrays are built up of microstrip patch antennas. However, most of the arrays in the papers referred to above use conventional microstrip antennas as the elements, and their bandwidths are narrow. Although some of them employ certain techniques for enhancing the bandwidths, such as aperture-coupling [8], triple patch [9], proximitycoupling with cavity-backed configuration [10], and E-shaped patch [11], the capability of increasing the bandwidths with techniques is limited, and the largest bandwidth achieved in these arrays is only $27.6 \%$ [10].

In this paper, we extend the cavity-backed proximitycoupled stacked patches antenna in our previous work [12] into the design of a broadband spherical conformal phased array antenna working in Ku-band. The array antenna consists of 19 single-column arrays with 13 elements. To achieve a wideband response of the embedded elements, the influences of the mutual couplings on the matching are included in the optimization. The measured results of the center embedded element in the prototype array demonstrate that its bandwidth is $42 \%$ (VSWR $<2$ ).

\section{Array Antenna Configuration and Mutual Coupling Analyses}

The array antenna is located on a spherical surface with a radius of about $153 \mathrm{~mm}$, which is shown in Figure 1.

In the array, 19 single-column arrays are spaced $5^{\circ}$ along the $\varphi$-direction, and there are 13 elements spaced $4^{\circ}$ 


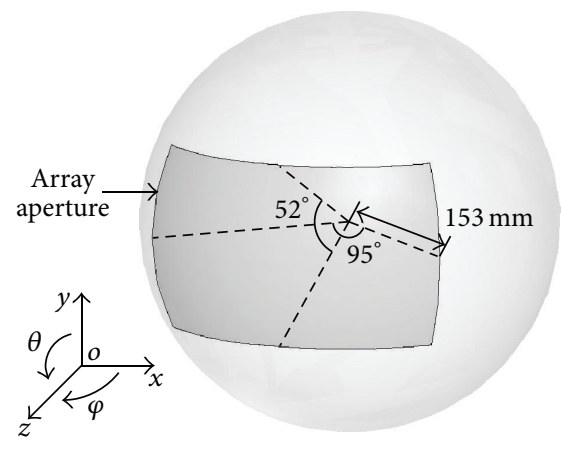

(a)

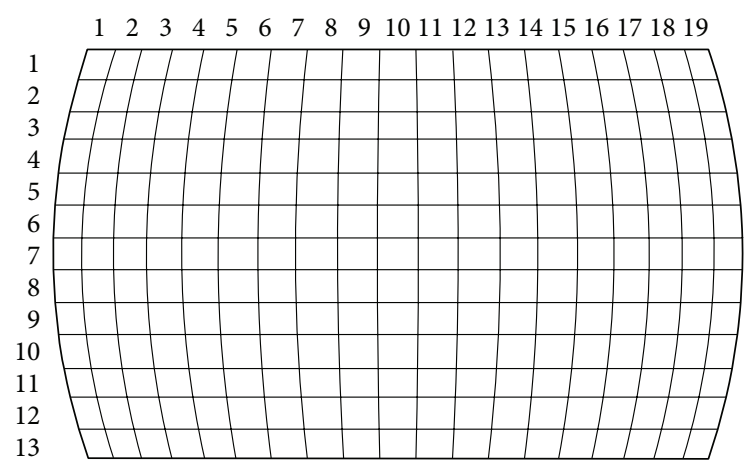

(b)

FIGURE 1: Sketch of the Ku-band spherical phased array antenna. (a) Geometry of the array. (b) Locations of the elements.

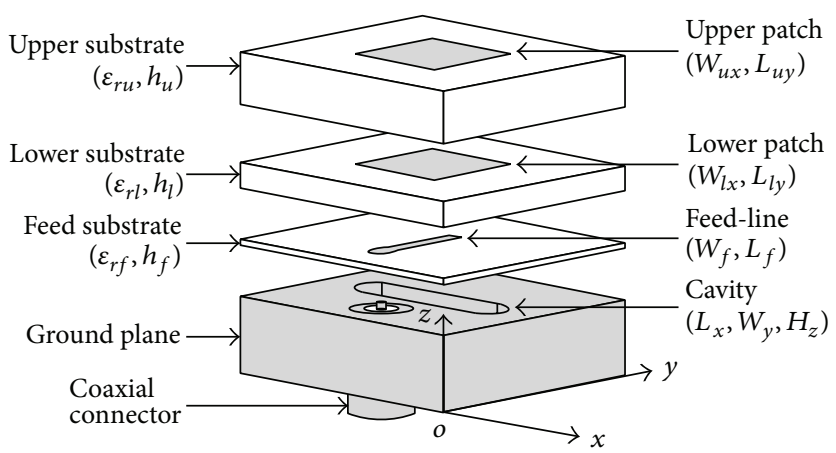

Figure 2: Geometry of the antenna element.

along the $\theta$-direction in each single-column array. The crosssections of the conformal array antenna in $x z$ - and $y z$ planes are two sectors with central angles of $95^{\circ}$ and $52^{\circ}$, respectively. Its embedded elements are assembled piecewise in a smoothly spherical metallic frame. The polarization of the antenna element is $\theta$ polarization, whose structure is depicted in Figure 2. The element is composed of two stacked patches, a cavity, a feed-line, and three substrate layers. $L_{f}$ is the distance between the open circuit termination of the feed-line with $W_{f}$ and the cavity surface center. The coaxial connector and the feed-line are vertically connected. The stacked patches and the cavity are to serve as three radiators with interactions, which affords a broadband solution [12].

Due to the limitation of the computing devices' capability, it is difficult to simulate the whole conformal array antenna with $13 \times 19$ elements. Hence, it is needed to reduce the simulated array size for improving computing efficiency in case of ensuring the effectiveness of the results. In order to obtain the reasonable simulated array size, the mutual couplings among elements in the seventh single-row array and the tenth single-column array are simulated by HFSS, separately. The elements in the two arrays are the same. Arlon DiClad880 is used as the substrate material. Its dielectric constant is 2.2. The thicknesses of the three substrates are $h_{f}=$ $0.254 \mathrm{~mm}, h_{l}=1.016 \mathrm{~mm}$, and $h_{u}=2.032 \mathrm{~mm}$. The other parameters are $W_{l x}=L_{l y}=4 \mathrm{~mm}, W_{u x}=L_{u y}=4.5 \mathrm{~mm}$, $L_{x}=7 \mathrm{~mm}, W_{y}=2 \mathrm{~mm}, H_{z}=2.2 \mathrm{~mm}, W_{f}=0.8 \mathrm{~mm}$, and $L_{f}=1.3 \mathrm{~mm}$. The simulated results are revealed in Figure 3. The magnitude of the mutual coupling between the two elements is $\left|S_{(i, j),(m, n)}\right|$, where $i$ and $\mathrm{m}$ as well as $j$ and $n$ are the row and the column numbers of the elements, respectively.

As can be seen from Figure 2, the $\varphi$-directed couplings decay rapidly with the increases of the distances between the two elements, and $\left|S_{(7,10),(7,12)}\right|$ is already lower than $-22 \mathrm{~dB}$ in the lower frequency band. However, the $\theta$-directed couplings do not exhibit a similar behavior. The mutual couplings between the center embedded element and other elements in the tenth single-column array are not decreased obviously with the increases of their distances, and $\left|S_{(7,10),(11,10)}\right|$ is still larger than $-20 \mathrm{~dB}$ in the lower frequency band. Accordingly, the effects of the mutual couplings on the matching of the embedded element in the $\theta$-direction are larger than those in the $\varphi$-direction. Considering these circumstances, a simulated array model with three single-column arrays composed of 9 elements is constructed.

\section{Array Antenna Design and Results}

Based on the proposed simulated model, the embedded element is optimized. In the optimization process, the parameters of the three substrates and the width of the feedline are invariable and their values are the same as the instance in Figure 3. By optimizing other design parameters 


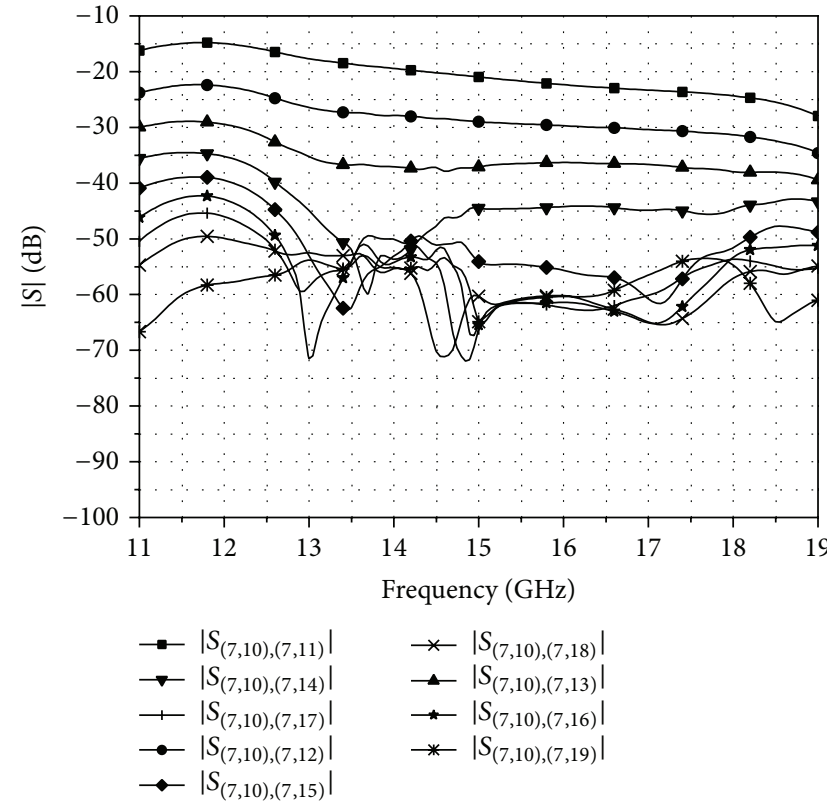

(a)

FIGURE 3: Mutual couplings between two separated elements. (a) Seventh single-row array. (b) Tenth single-column array.

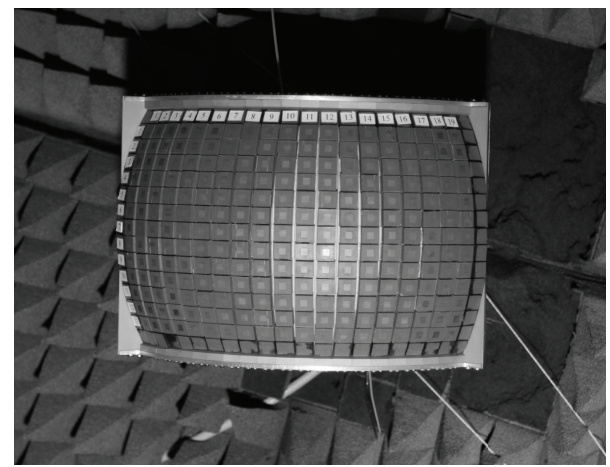

FIGURE 4: Prototype of spherical conformal phased array antenna.

of the embedded element, a great matching performance is achieved. Their values are listed as follows: $W_{l x}=L_{l y}=$ $4.25 \mathrm{~mm}, W_{u x}=L_{u y}=4.3 \mathrm{~mm}, L_{x}=6 \mathrm{~mm}, W_{y}=1.8 \mathrm{~mm}$, $H_{z}=2.5 \mathrm{~mm}$, and $L_{f}=1.3 \mathrm{~mm}$. With these parameters, a 13 $\times 19$ prototype conformal array antenna is fabricated, which is shown in Figure 4.

Figure 5 shows the measured and the simulated results of the center embedded element VSWR and the magnitude of the mutual couplings between two neighboring elements. It can be seen that the measured bandwidth of VSWR below 2 is from 12 to $18.4 \mathrm{GHz}(42.1 \%)$ and the simulated bandwidth is from 11.8 to $18.5 \mathrm{GHz}(44.2 \%)$. Both of the measured and the simulated mutual couplings in the $\theta$-direction $\left(\left|S_{(7,10),(8,10)}\right|\right)$ are lower than $-16 \mathrm{~dB}$, and the measured and the simulated mutual couplings in the $\varphi$-direction $\left(\left|S_{(7,10),(7,11)}\right|\right)$ are both lower than $-18 \mathrm{~dB}$. Also, the measured and the simulated results are in agreement, which means it is effective that the

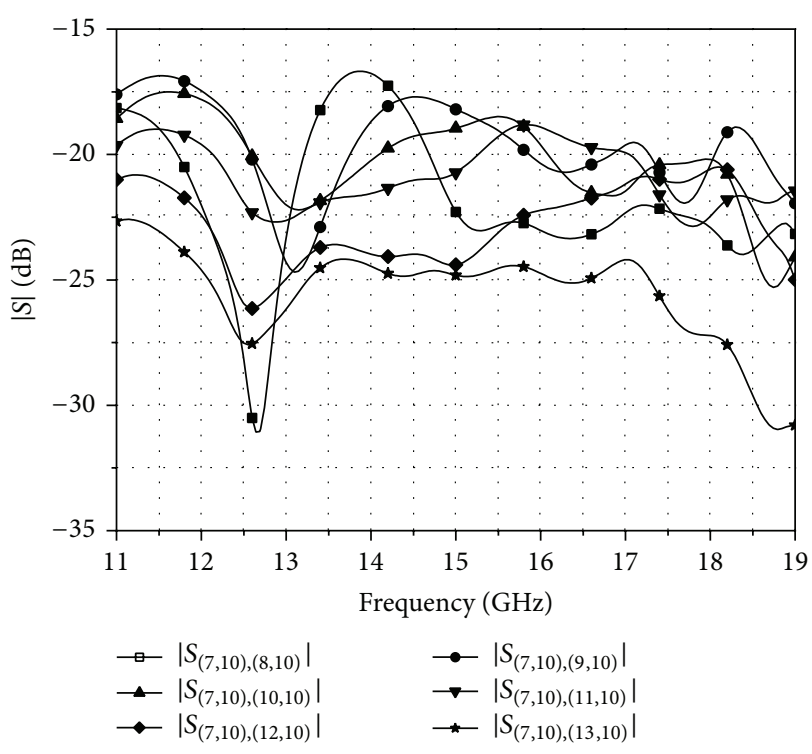

(b)

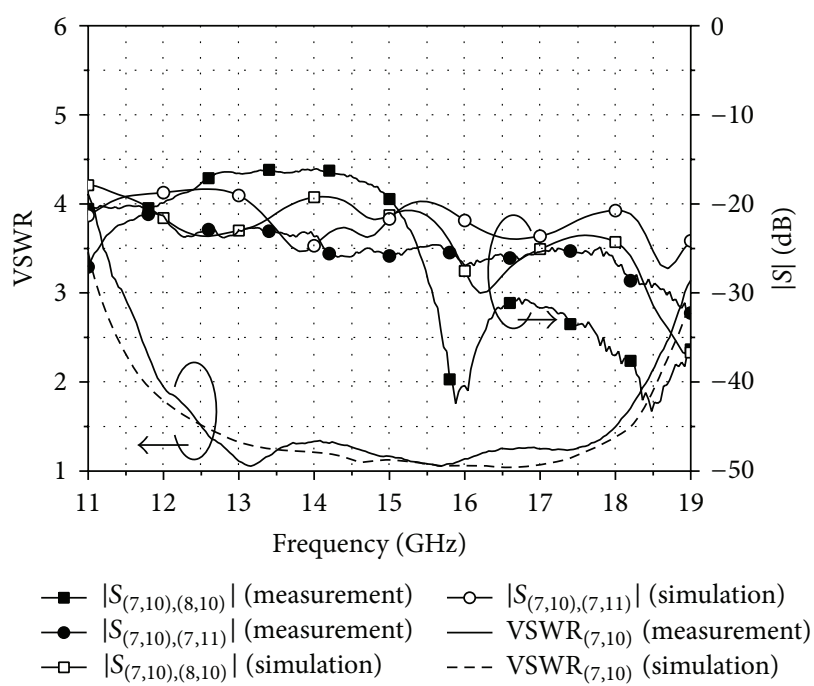

FIgURE 5: Measured and simulated results of VSWR and mutual couplings.

matching performance of the center embedded element in the whole array is estimated by simulating the small size array proposed above.

The radiation patterns of the center embedded element in the operation band are shown in Figure 6. The copolar patterns exhibit good symmetry, and the measured crosspolarization levels are less than $-17 \mathrm{~dB}$. Due to the different sizes of the arrays and the ground planes of the simulated model and the actual prototype, there are different oscillating behaviors in the simulated and the measured patterns, especially in the E plane. Figure 7 reveals the gain of 


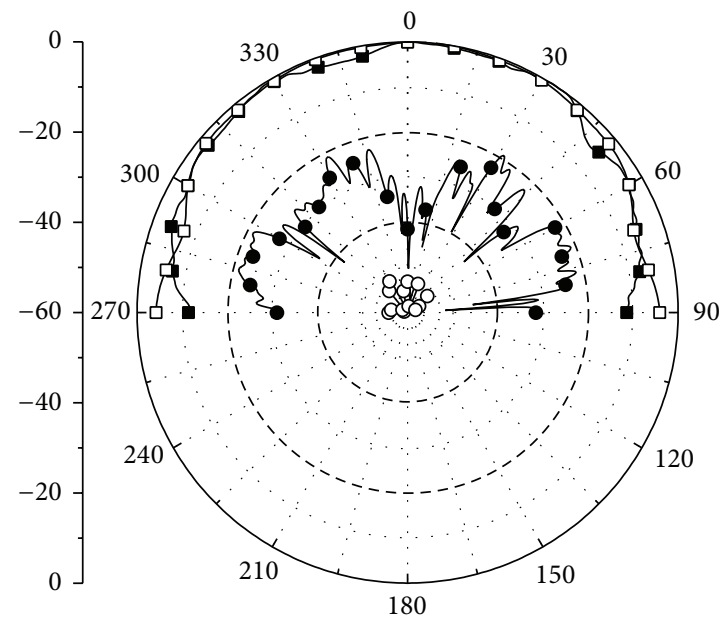

(a)

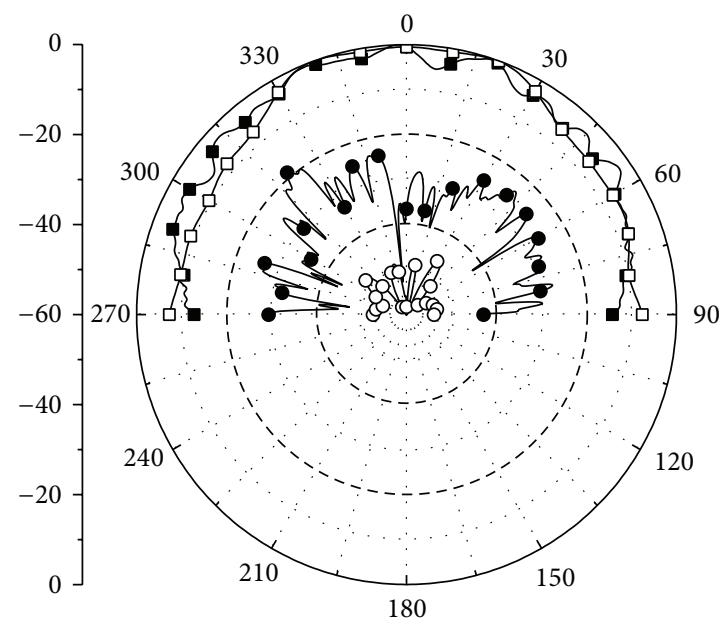

(c)

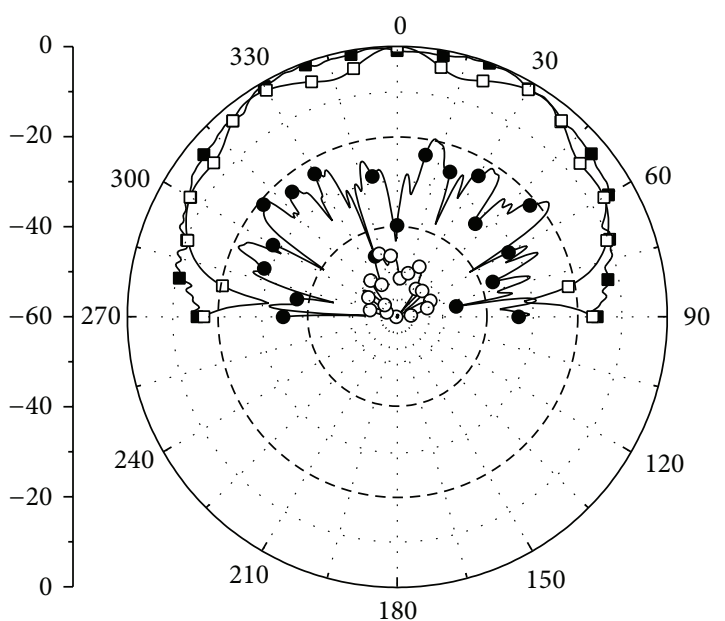

$\rightarrow$ Copol. (measurement) $\quad-\square-$ Copol. (simulation)

- Cross-pol. (measurement) $\multimap-$ Cross-pol. (simulation)

(e)

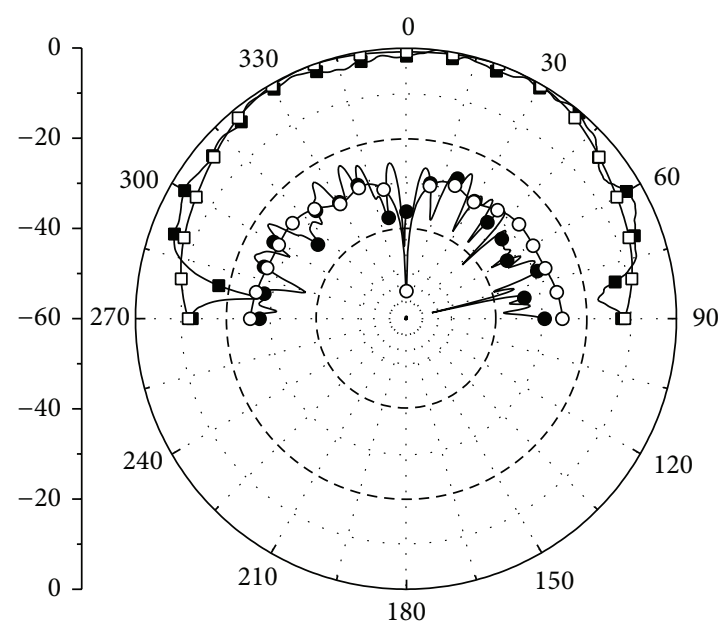

(b)

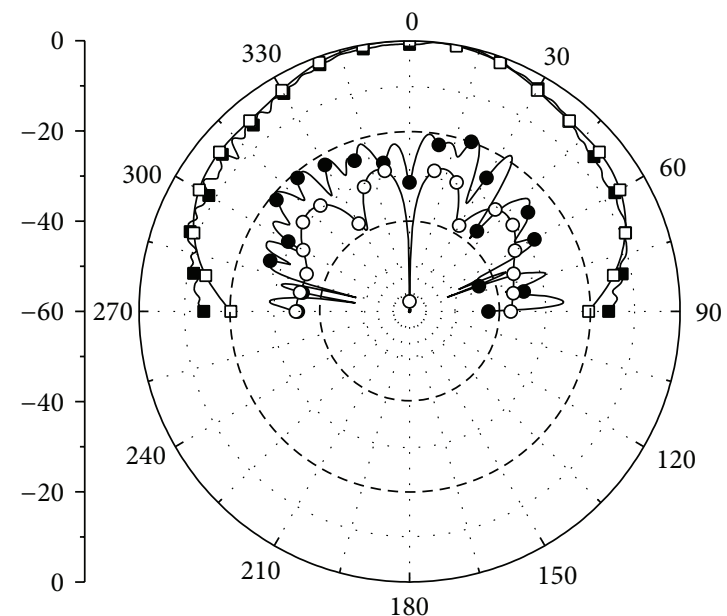

(d)

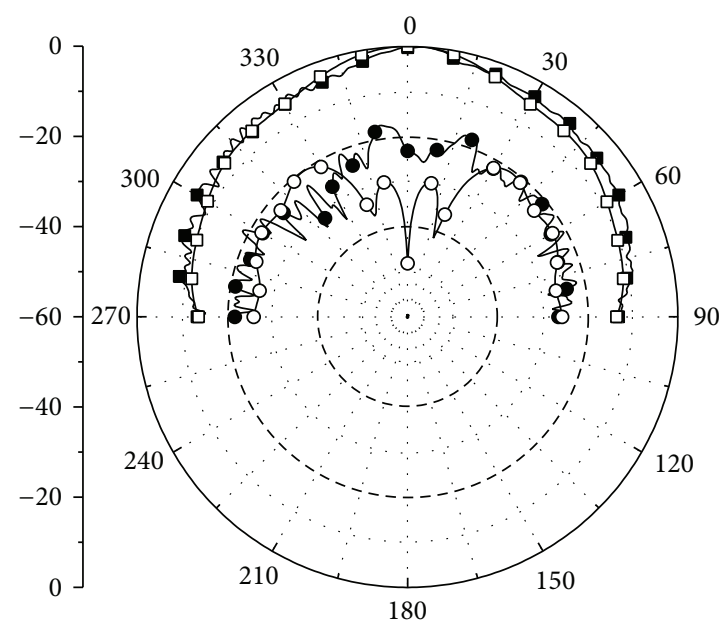

$\rightarrow$ Copol. (measurement) $\quad \rightarrow-$ Copol. (simulation)

- Cross-pol. (measurement) -0 - Cross-pol. (simulation)

(f)

FIGURE 6: Measured and simulated radiation patterns of the central element at different frequencies. (a) E plane at $12 \mathrm{GHz}$. (b) $\mathrm{H}$ plane at $12 \mathrm{GHz}$. (c) E plane at $15 \mathrm{GHz}$. (d) H plane at $15 \mathrm{GHz}$. (e) E plane at $18 \mathrm{GHz}$. (f) $\mathrm{H}$ plane at $18 \mathrm{GHz}$. 


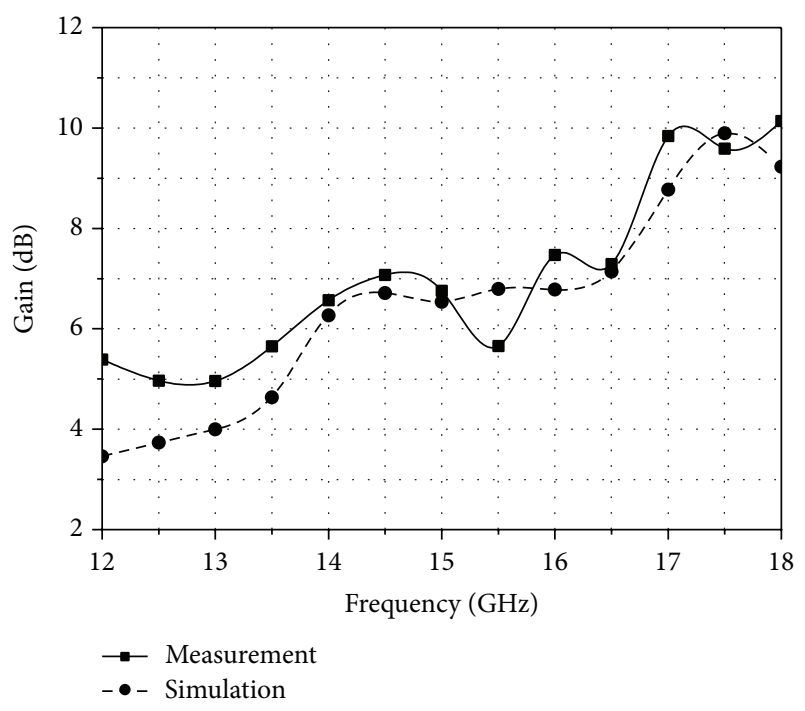

FIGURE 7: Measured and simulated gain of the center embedded element.

the center embedded element in the operation band. As can been seen from the measured and simulated results, the trends of the two curves are comparatively consistent. The measured and the simulated maximum gains are $10.1 \mathrm{~dB}$ at $18 \mathrm{GHz}$ and $9.9 \mathrm{~dB}$ at $17.5 \mathrm{GHz}$, separately.

\section{Conclusion}

A Ku-band spherical conformal phased array antenna has been designed in this paper. The simulated results of $9 \times$ 3 array estimate accurately the matching performances of the embedded element in the actual array. In the meantime, the method provides a nice computing efficiency. The center embedded element of the array exhibits an excellent broadband over $40 \%$ (VSWR $<2$ ) and a good radiation performance, which indicates that the method is effective. The array is suitable for being applied to radar and communication systems in aircrafts and other mobile platforms with limited space.

\section{Conflict of Interests}

The authors declare that there is no conflict of interests regarding the publication of this paper.

\section{References}

[1] Z. Sipus, P. Persson, M. Lanne et al., "Structuring research on conformal antennas a European collaboration," in Proceedings of the 2nd European Conference on Antennas and Propagation (EuCAP '07), pp. 1-4, November 2007.

[2] Q. Wu, M. Liu, and Z.-R. Feng, "A millimeter-wave conformal phased microstrip antenna array on a cylindrical surface," in Proceedings of the IEEE International Symposium on Antennas and Propagation and USNC/URSI National Radio Science Meeting (APSURSI '08), pp. 1-4, July 2008.
[3] J. C. Brégains, L. Castedo, and F. Ares-Pena, "A WiMAX conformal broad-beam antenna," IEEE Antennas and Propagation Magazine, vol. 52, no. 6, pp. 106-109, 2010.

[4] Y. Zhou, Y. Bayram, F. Du, L. Dai, and J. L. Volakis, "Polymercarbon nanotube sheets for conformal load bearing antennas," IEEE Transactions on Antennas and Propagation, vol. 58, no. 7, pp. 2169-2175, 2010.

[5] D. T. Pham, H. Subbaraman, M. Y. Chen, X. Xu, and R. T. Chen, "Light weight and conformal 2-bit, $1 \times 4$ phased-array antenna with CNT-TFT-based phase shifter on a flexible substrate," IEEE Transactions on Antennas and Propagation, vol. 59, no. 12, pp. 4553-4558, 2011.

[6] C.-H. Ahn, Y.-J. Ren, and K. Chang, "A dual-polarized cylindrical conformal array antenna suitable for unmanned aerial vehicles," International Journal of RF and Microwave ComputerAided Engineering, vol. 21, no. 1, pp. 91-98, 2011.

[7] V. Semkin, M. Kyrö, V.-M. Kolmonen et al., "Conformal antenna array for $60 \mathrm{GHz}$ applications," in Proceedings of the 7th European Conference on Antennas and Propagation, pp. 605608, April 2013.

[8] P. Knott, "Antenna design and beamforming for a conformal antenna array demonstrator," in Proceedings of the IEEE Aerospace Conference, pp. 1-7, March 2006.

[9] P. Knott, "Design and experimental results of a spherical antenna array for a conformal array demonstrator," in Proceedings of the 2nd International ITG Conference on Antennas (INICA '07), pp. 120-123, March 2007.

[10] D. Sun, W. Dou, and L. You, "Application of novel cavity-backed proximity-coupled microstrip patch antenna to design broadband conformal phased array," IEEE Antennas and Wireless Propagation Letters, vol. 9, pp. 1010-1013, 2010.

[11] J. K. H. Gamage, B. Holter, I. A. Jensen, K. Husby, and J. Kuhnle, "A wideband conformal antenna array for cognitive radio/MIMO applications," in Proceedings of 5th European Conference on Antennas and Propagation (EUCAP '11), pp. 725729, April 2011.

[12] D. Sun, W. Dou, L. You, X. Yan, and R. Shen, "A broadband proximity-coupled stacked microstrip antenna with cavitybacked configuration," IEEE Antennas and Wireless Propagation Letters, vol. 10, pp. 1055-1058, 2011. 

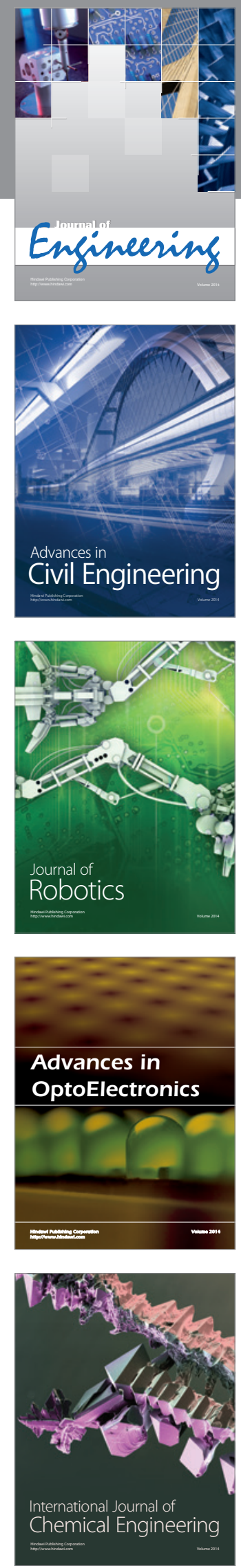

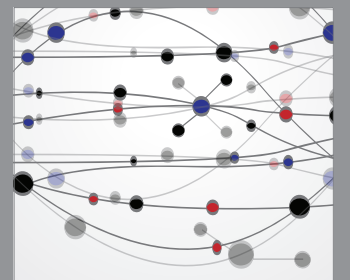

The Scientific World Journal
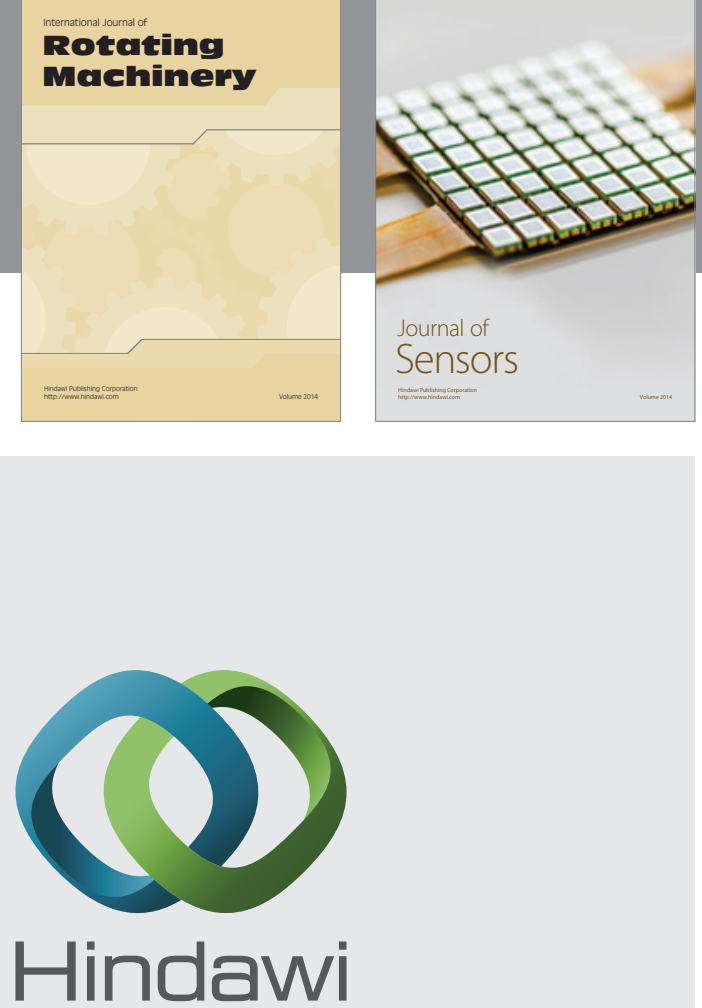

Submit your manuscripts at http://www.hindawi.com
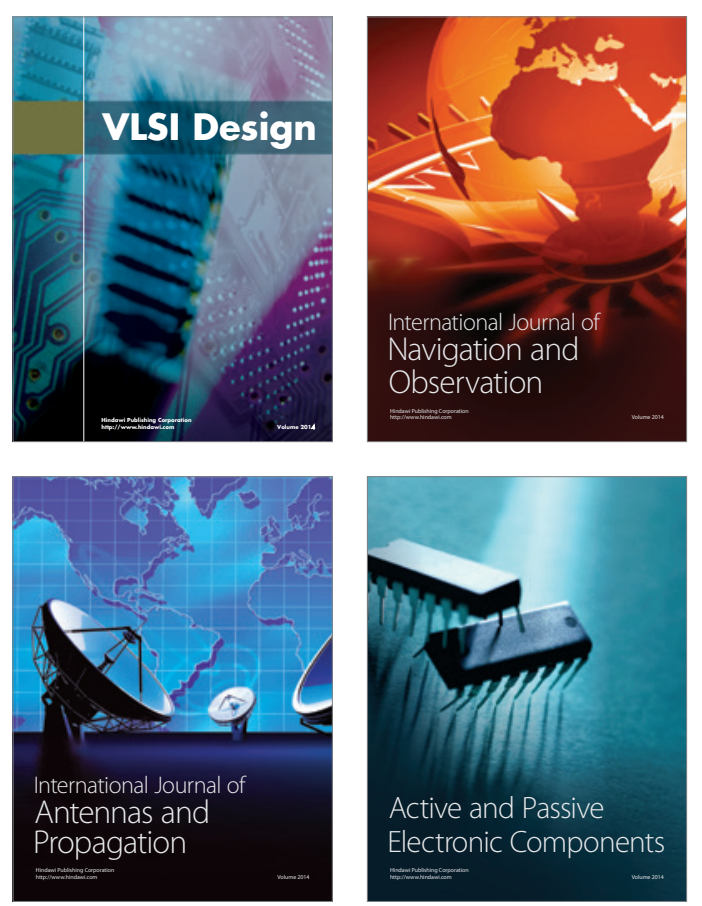
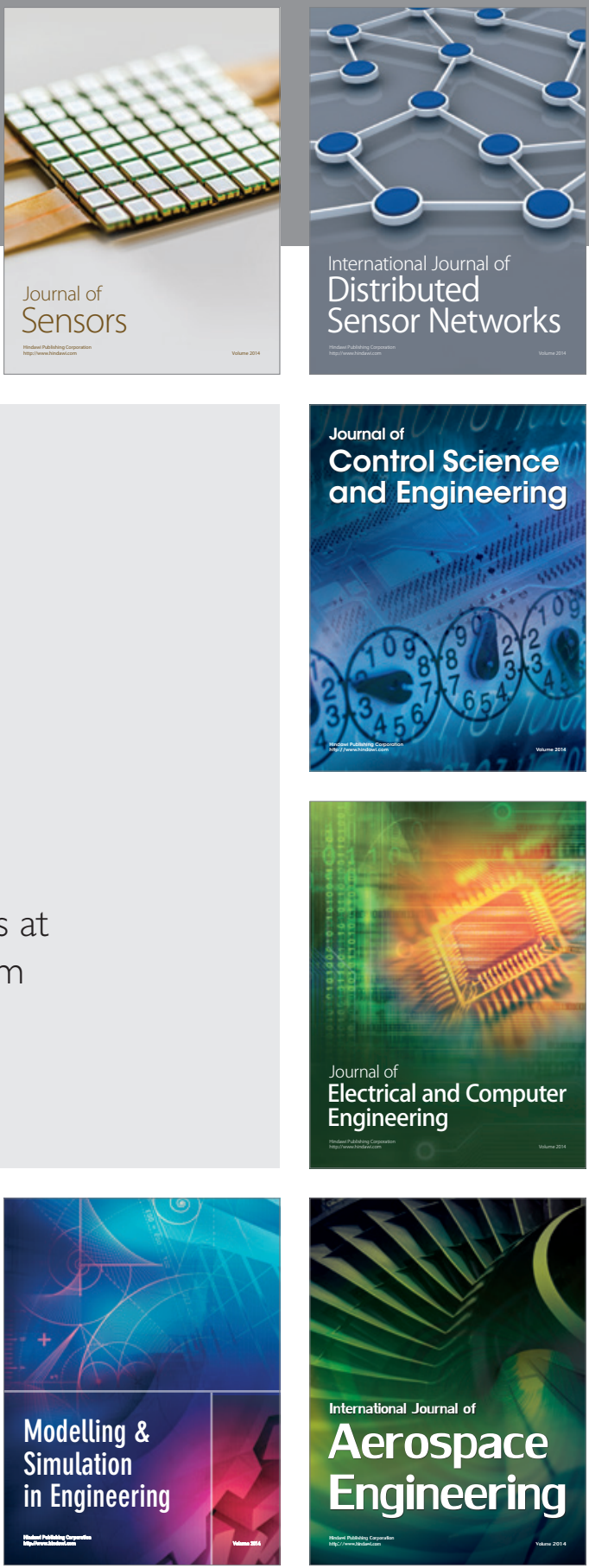

Journal of

Control Science

and Engineering
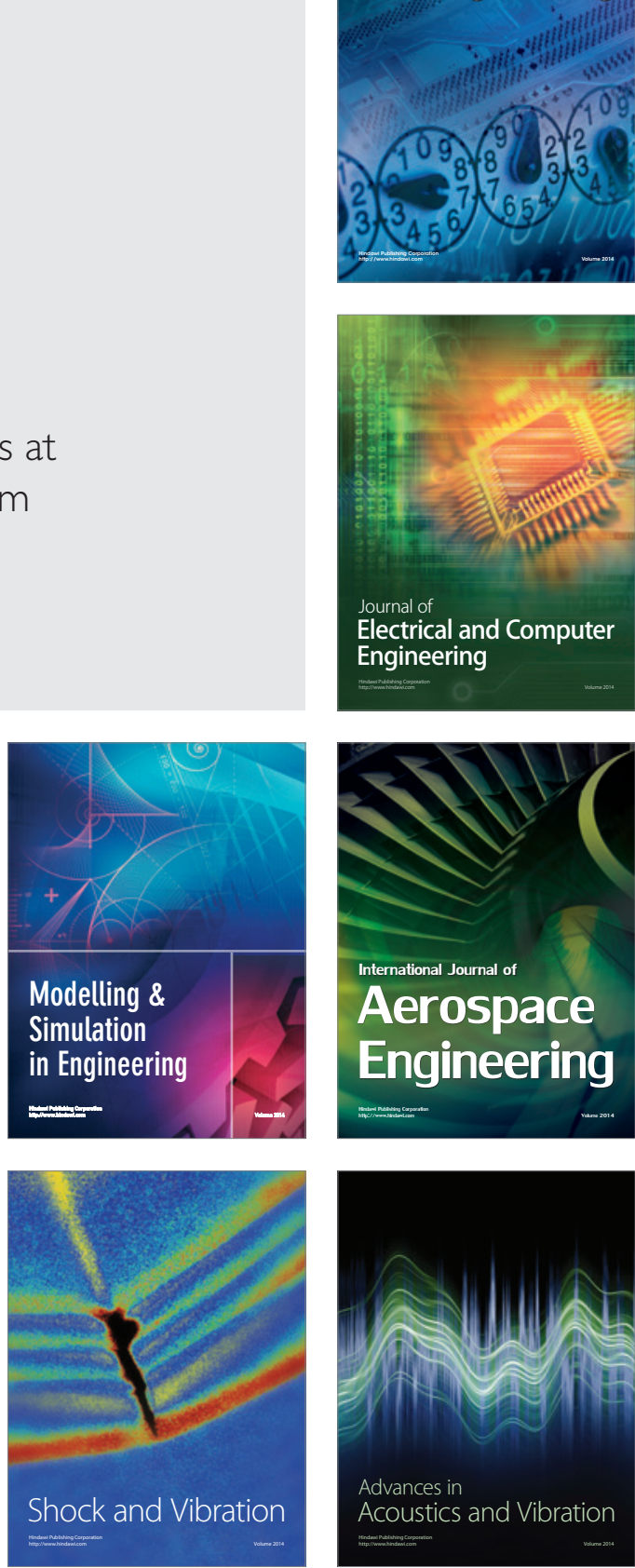